\title{
A STUDY ON CORRELATION BETWEEN HARDNESS AND THERMAL CONDUCTIVITY OF POLYMER COMPOSITES REINFORCED WITH STINGING NETTLE FIBER
}

\author{
I.G.P. Agus Suryawan, N.P.G. Suardana, I.N. Suprapta Winaya, I.W. Budiarsa Suyasa \\ Doctoral Program of Engineering, Faculty of Engineering, \\ Udayana University, Indonesia
}

\begin{abstract}
The advantages of the fibrous nature of stinging nettles compared with other natural fibers are their strength and light weight. Stinging nettles thrive in Indonesia, Asia. Nettle fiber is used as a substitute for synthetic fibers to reinforce composite materials. The objective of this research was to study the relationship between the hardness and thermal conductivity of polymer composites reinforced with nettle fiber. Epoxy composites were reinforced with nettle fiber using fiber weight fractions of $10 \%, 15 \%$, and 20\%. Fibers were treated with 5\% NaOH for 2 hours, had a length of $5 \mathrm{~mm}$, and were in a random orientation. Composites were produced using the hand lay-up method. The results show that the composite hardness were 81.6, 84.4, and 86.6 Shore D, and the thermal conductivities were 0.129, 0.138, and $0.162 \mathrm{kcal} / \mathrm{ms}{ }^{\circ} \mathrm{C}$. The relationship between control factors and performance output was determined by nonlinear regression analysis.
\end{abstract}

Keywords: stinging nettle, composite, hardness and thermal conductivity.

Cite this Article: I.G.P. Agus Suryawan, N.P.G. Suardana, I.N. Suprapta Winaya, I.W. Budiarsa Suyasa, A Study on Correlation Between Hardness and Thermal Conductivity of Polymer Composites Reinforced with Stinging Nettle Fiber. International Journal of Civil Engineering and Technology 11(1), 2020, 94-104.

http://iaeme.com/Home/issue/IJCIET?Volume=11\&Issue=1

\section{INTRODUCTION}

Epoxy-matrix composites that are reinforced with stinging nettle fiber are being developed as an alternative material to synthetic composites and metal. This substitution is possible because nettle fibers are characterized by strength and light weight. Stinging nettle is a plant with fiber on its stem and is suitable for cultivation in Indonesia, Asia. Stinging nettle grows abundantly in Bali, Indonesia, especially in Pupuan. It is an annual plant that grows for about 1 year and needs fertile soil to grow well.

Polymer materials such as polyethylene (PE), epoxy and polypropylene (PP) are wellknown as good thermal isolators. 
Some microelectronic systems contain electronic devices that require thermal insulation with high thermal conductivity so that the component does not become too hot. In such cases, composites are useful as isolators for the removal of excessive heat, for example building interiors.

A study revealed that the technical specifications of stinging nettle fiber made it a promising material for composite reinforcement. These favorable properties of stinging nettle fiber included Young's modulus of $87 \pm 28 \mathrm{GPa}$, a tensile strength of $1594 \pm 640 \mathrm{MPa}$, a strain at break of $2.11 \% \pm 0.81 \%$, and an average diameter of $19.9 \pm 4.4 \mu \mathrm{m}$ (Bodros and Baley 2008) [5].

Several researchers have proved that stinging nettle fiber has a high potential for strengthening composite materials. Special treatment is required to produce fine stinging nettle fiber with high tensile strength (Bacci et al. 2009) [3], study of nettle (Bacci et al. 2011; Di Virgilio et al. 2015; Akgül 2013; Paukszta et al. 2013; Klimesova 1995; Boufford 1992; Suryawan et al. 2017) [4, 21, 1, 15, 9, 6, 20].

A study on polylactic acid (PLA) reinforced by stinging nettle fiber compared $20 \%, 30 \%$, and $40 \%$ fiber weights, and the resulting composite material tensile strengths were 45,59 , and $40 \mathrm{MPa}$, respectively. The tensile strength of PLA without fiber reinforcement was $52 \mathrm{MPa}$ (Fischer et al. 2012) [7].

A study was conducted to measure the Shore A hardness of materials made from plastic, rubber, and composite compared with the results of the Vickers hardness test, which is commonly used in industry. The required specimen thickness is $6 \mathrm{~mm}$ without correction (Spa, Elastomeri, and Milanese 1987) [19]. Shore D durometer is a hardness measuring instrument for assessing materials that are harder than those measured by a Shore A durometer.

Study on the polypropylene composites reinforced with alkaline-treated pineapple leaf fiber $(30,40,50,60$, and $70 \mathrm{wt} \%)$ from the Josapine cultivar, research results are the highest hardness value 65.38 Shore D, was obtained with $70 \mathrm{wt} \%$ leaf fiber (Kasim, et al. 2016) [8].

Study of thermal conductivity in natural fiber reinforced composites (Liu et al. 2014; Nikmatin et al. 2017; Mohapatra et al. 2014; Panthapulakkal \& Sain 2007; Ray et al. 2002) $[10,12,11,13,16]$. Another study on thermal conductivity and its relation with wear resistance using natural fiber-reinforced epoxy resin composite (Patnaik et al. 2010) [14].

Application of natural fiber (luffa) as a concrete mixture, the addition of $1 \%$ and $2 \%$ of luffa the compression, tension and flexural test results are increasing (Sen \& Ankit 2018) [17]. Composites can be made in hybrid composites or bio composites, testing and processing of mechanical properties of hybrid composites using graphene/epoxy with alumina (Shetty 2019) [18], while the process of degradable hybrid natural fiber polymer composites (Alex \& Retnam 2014) [2].

\section{MATERIALS \& EXPERIMENTAL PROCEDURES}

\subsection{Materials}

Stinging nettle stem was harvested from Pupuan, Tabanan, Bali Indonesia and each plant harvested was at least $50 \mathrm{~cm}$ in height, so specimens shared the same physical characteristics. The harvested stem was sun-dried and then soaked in water to extract the fiber. The fiber was taken by decortication, i.e., fiber was carefully separated from the bark using a simple tool or by hand. The retting process is carried out at the Laboratory of Basic Mechanical Engineering Phenomenon, Udayana University. The stinging nettle fiber has an average density of 0.72 $\mathrm{g} / \mathrm{cm}^{3}$ and high specific rigidity (Bacci et al. 2009). 


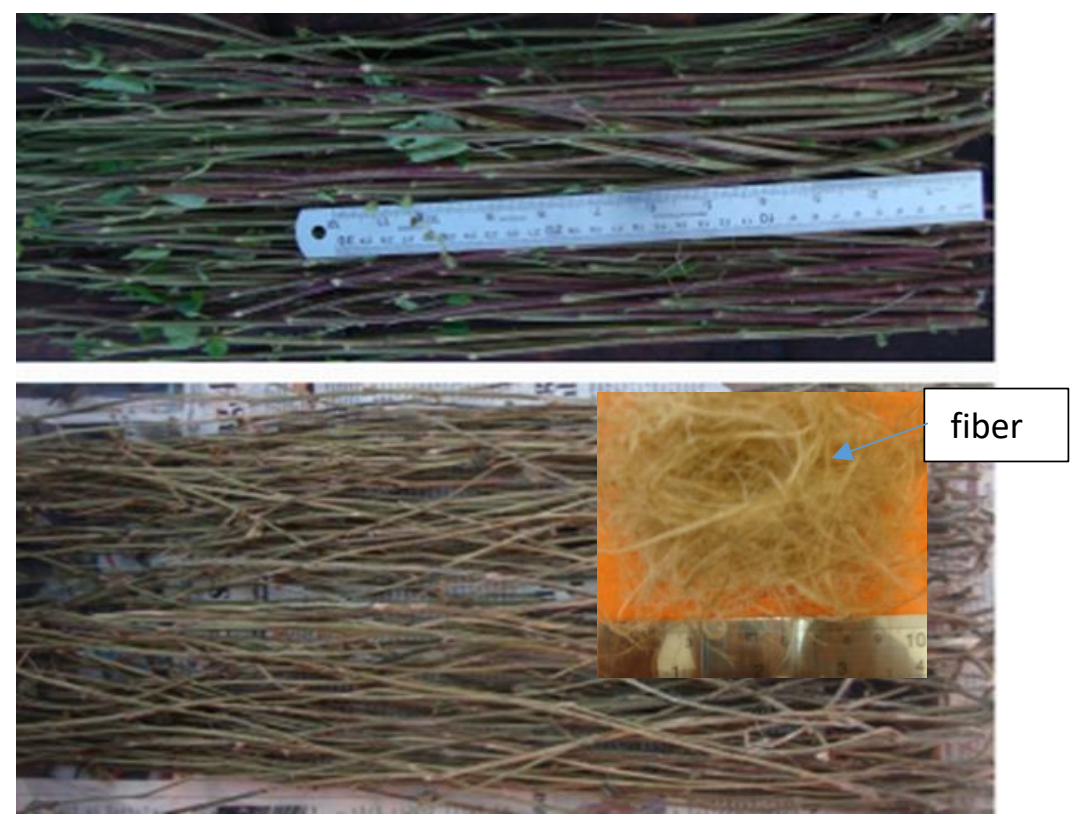

Figure 1. Wet and dried stinging nettle stem

Epoxy resin and hardener, which were bought online through CV Subur Kimia Jaya Bandung Indonesia, were used to form the matrix. Stinging nettle was harvested from Pupuan, Tabanan Bali, Indonesia. Distilled water was used to wash the fiber, and $\mathrm{NaOH}$ was used to remove lignin from the fiber. Glycerin was applied so that the composite material did not stick to the mold. $\mathrm{NaOH}$ and glycerin is supplied from PT. Brataco Ltd (Indonesia).

Table 1 Epoxy properties

\begin{tabular}{clcc}
\hline NO & \multicolumn{1}{c}{ Properties } & Value & Unit \\
\hline 1 & density & $1.10-1.40$ & $\mathrm{~g} / \mathrm{cm}^{3}$ \\
2 & tensile strength & 58.50 & $\mathrm{MPa}$ \\
3 & Young's modulus & 3.5 & $\mathrm{GPa}$ \\
4 & elongation & 1.4 & $\%$ \\
5 & flexural strength & 80.82 & $\mathrm{MPa}$ \\
\hline
\end{tabular}

\subsection{Research Tools}

A scale with a precision of $0.01 \mathrm{~g}$ was used to weigh the resin and fiber. The composite mold was made from glass. Other measurement tools used were calipers, presses, and cutting machines used for finishing. Material fabrication and hardness testing were conducted in the Laboratory of Basic Mechanical Engineering Phenomenon, Udayana University. Hardness testing with Shore Hardness Tester, Model NO: TA 300, Oingdao Tlead International Co., Ltd, made in China. Thermal conductivity was tested using a Thermal Conductivity Measuring Apparatus (model HVS-40-200 SE), Tokyo Meter Co. Ltd, Japan. That was done at Gajah Mada University. Microstructures were observed using a JEOL JSM-651OLA analytical scanning electron microscope (SEM) made in Japan.

\subsection{Composite Specimen Molding}

Composite molding begins by soaking nettle fibers with a $5 \% \mathrm{NaOH}$ treatment for 2 hours then washing with distilled water and subsequently dried in an oven at $80{ }^{\circ} \mathrm{C}$ for 12 hours. Strengthener and binder were prepared by calculating the weight percentage. Glycerin was spread thinly and evenly on the inner part of the composite. Resin and a catalyst were mixed for a proportion of $1 \%$ catalyst in a measuring cup, after which the two components were 
stirred until evenly mixed. Stinging nettle fiber was put into the resin/catalyst mixture and stirred until evenly mixed. The mixture of fiber and resin was poured into a mold, flattened, and given a pressure of $10 \mathrm{psi}$ so that the strengthener and binder were evenly distributed to all parts of the mold. The composite specimen hardened in 24 hours.

\subsection{Observation of the Composite's Physical Form}

As a test specimen, the composite was considered homogeneous and successfully fabricated if it did not show signs of breaking, cracking, or deformation and if the void did not gather in one place. The curves of successfully produced composites were observed by placing the composite sheet on glass.

\section{METHOD}

\subsection{Research Design}

This study investigates the effect of the weight fiber fraction $(10 \%, 15 \%$, and $20 \%)$ of stinging nettle fiber on its reinforcement of epoxy composite material according to the hardness and thermal conductivity of the composite. The specimen material is produced by hand lay-up method, the fiber length is $5 \mathrm{~mm}$ and the orientation of the fiber is random.

Fibers orientation is not always feasible to create a polymer composite object with the desired shape and orientation of fiber, which can be in a longitudinal or transversal direction. Therefore, a more practical method is required to improve the thermal conductivity of polymer composites with a random orientation.

The composite sample for the SEM test is taken from the hardness sample that has been tested. It was cut into pieces with a length of $1 \mathrm{~cm}$ and width of $1 \mathrm{~cm}$. Samples were prepared by covering specimens with a thin coat of gold, and SEM imaging was performed. Sample in wet condition, mode of SEM in high vacuum, resolution mode is $30 \mathrm{X}$, working distance 18 $\mathrm{mm}$ and high voltage.

\subsection{Hardness Test}

Hardness tests were conducted using a Shore D durometer. This is an effective and simple method because the instrument is removed easily and provides a picture of the mechanical characteristics of the material. Testing is done 12 points for one sample, at least $1 \mathrm{~cm}$ from the edge of the material. The process is repeated for 5 samples. The dimensions of the hardness sample are $5 \times 5 \mathrm{~cm}$ with a thickness of $6 \mathrm{~mm}$, an optimum thickness according to research (Spa et al. 1987).
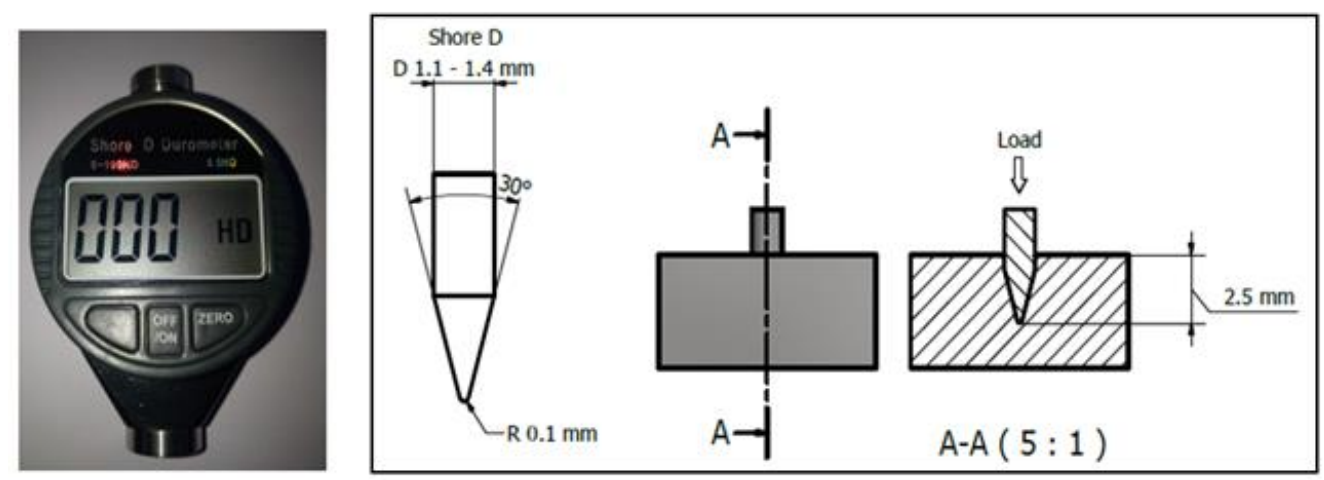

Figure 2. Shore D hardness test tool

Shore D hardness testing or Shore durometer testing was used to measure the hardness of rubber, plastic, and composite materials. 
The principle that was used to measure hardness was based on the resistance strength of the needle penetrating the test material under a known spring load. The result of this test was used to compare the hardness of various polymer classes. However, the Shore D hardness test was not suitable for comparing other measurements, such as scratch and abrasion resistance.

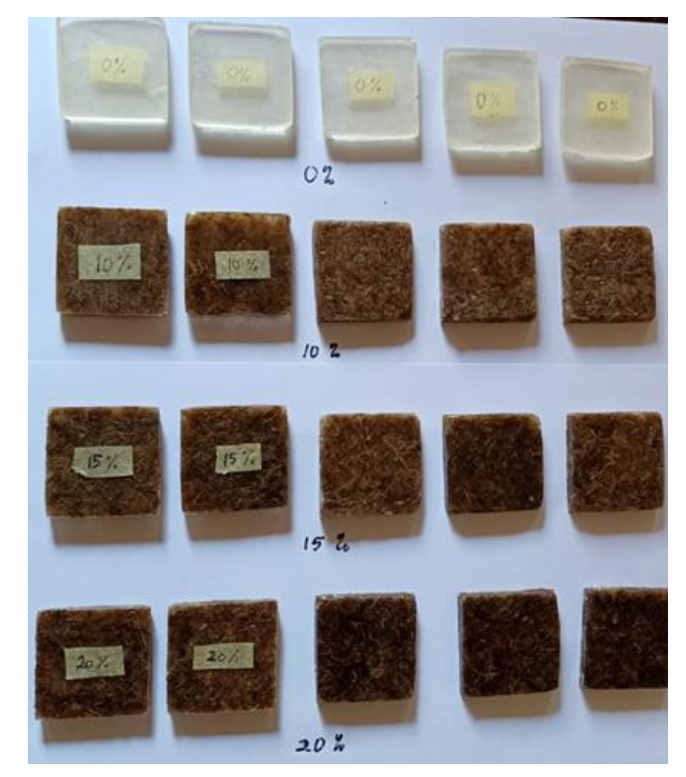

Figure 3. Hardness Test Specimens

\subsection{Thermal Conductivity Equation}

The thermal conductivity of a material determines the value of the thermal transfer that occurs. If the material's thermal conductivity is high, then the thermal transfer rate is high. High thermal conductivity is indicative of a good thermal conductor, while low thermal conductivity indicates that the material is an isolator.

The value of thermal conductivity was calculated by using the equation from ASTM E 1225 , i.e.:

$$
Q_{x}=-k A \frac{d T}{d X}
$$

where $\mathrm{Q}_{\mathrm{x}}$ is the heat flux $(\mathrm{W}), \mathrm{k}$ is the thermal conductivity $(\mathrm{W} / \mathrm{m} \mathrm{K})$, $\mathrm{dT}$ is the difference in temperature $(\mathrm{K}), \mathrm{dX}$ is the difference thickness, and $\mathrm{A}$ is the cross-section area of the sample $\left(\mathrm{m}^{2}\right)$. The value of heat conductivity is calculated from equation 2 .

$$
k=-\frac{Q_{x} d X}{A d T}
$$
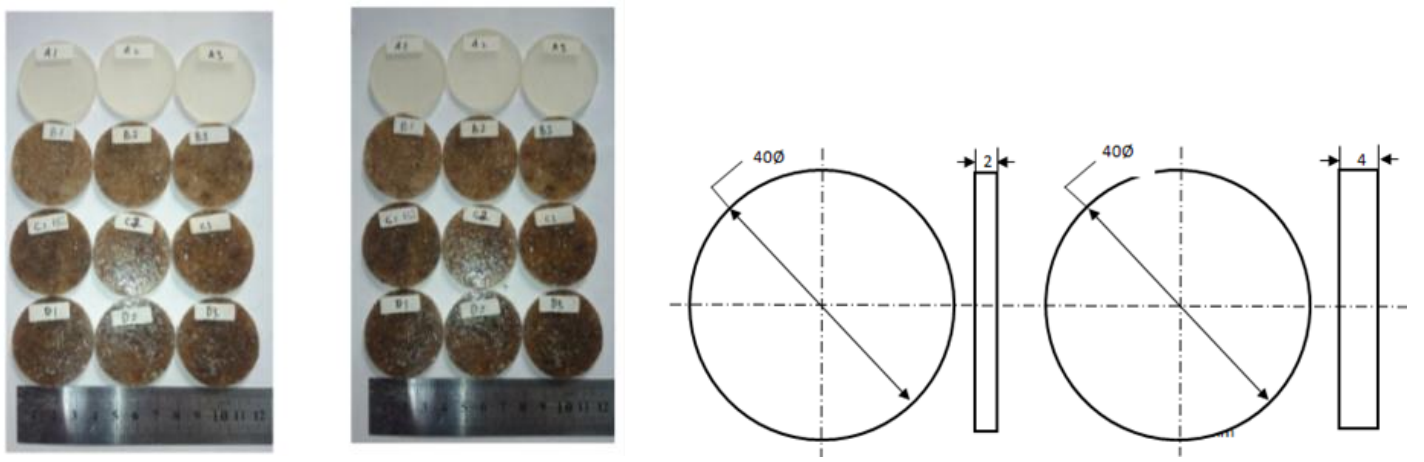

Figure 4. Thermal conductivity specimens 


\subsection{Thermal Conductivity Test}

Thermal conductivity was tested using a Thermal Conductivity Measuring Apparatus for which the test material was required to be round with a diameter of $40 \mathrm{~mm}$ and thicknesses of 4 and $2 \mathrm{~mm}$ for one test. Variables were measured in triplicate. Specimens were installed in two parts of the copper cylinder, which was loosened according to the thickness of the specimen, and then the top nut of the tube was tightened. Water was used as a coolant and streamed through the nose.
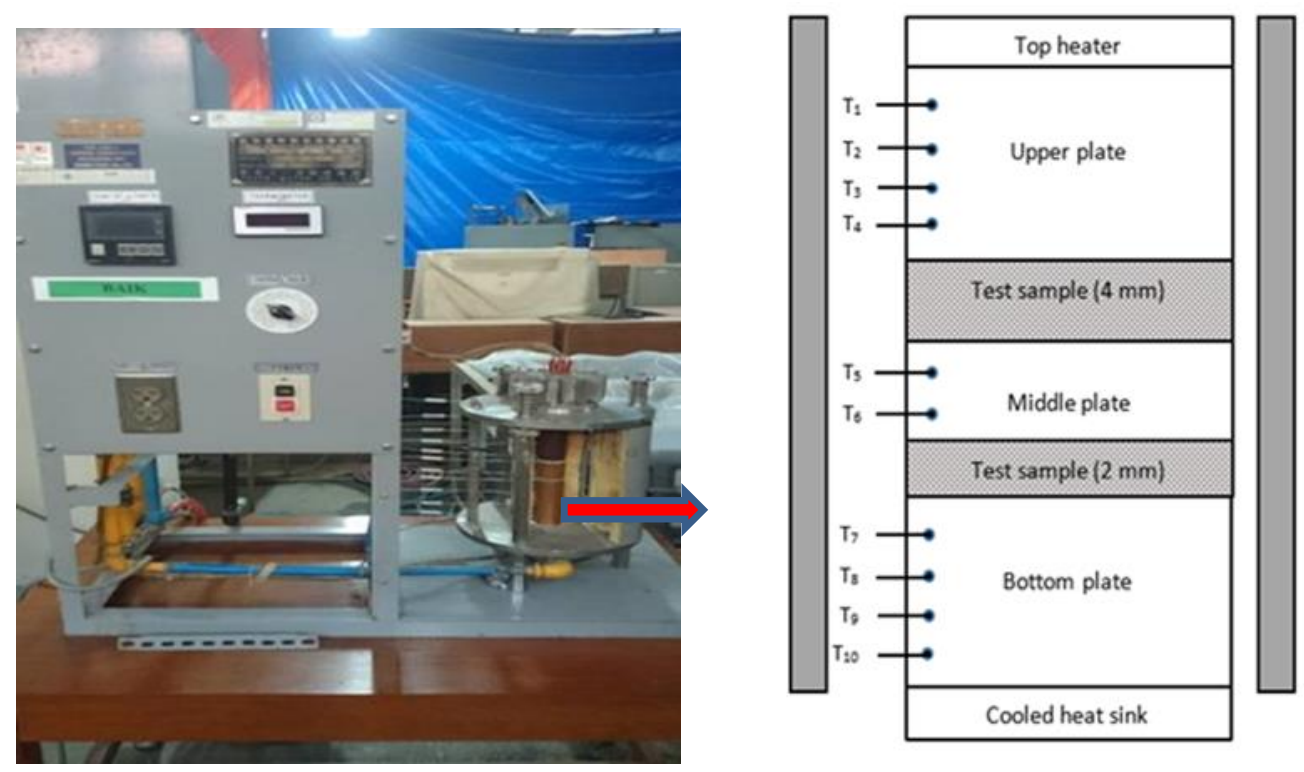

Figure 5. Thermal conductivity test tool

The electrical voltage was $220 \mathrm{~V}$, and the temperature was set to $110{ }^{\circ} \mathrm{C}$. Temperature was displayed on panel and monitored, and each temperatures in every thermocouple position was recorded.

\section{RESULT AND DISCUSSION}

\subsection{The Result of Hardness Testing}

The result of Shore D hardness testing can be seen in Figure 6, which shows that the hardness of stinging nettle-reinforced composite increased with the increase in the fiber weight fraction. Matrix without fiber, the hardness was $70.7 \pm 1.40$ Shore $D$; With a $10 \%$ fiber weight fraction, the hardness was $81.6 \pm 1.71$ Shore $\mathrm{D}$; with a $15 \%$ fiber weight fraction, the hardness was $84.4 \pm 1.39$ Shore $\mathrm{D}$; and with a $20 \%$ fiber weight fraction, the hardness was $86.6 \pm 1.43$ Shore D.

The addition of fiber weight fraction increases the hardness of the composite material. It is caused by the increasing number of fibers in the composite. A material that has a high tensile strength will also have a high hardness. This is in line with the results of the study where the tensile strength of the matrix is $58.50 \mathrm{MPa}$ (Table 1) while the tensile strength of a single fiber is on average $1594 \mathrm{MPa}$ (Bodros and Baley 2008). So that the greater the fiber weight fraction, the higher the hardness. 
A Study on Correlation Between Hardness and Thermal Conductivity of Polymer Composites Reinforced with Stinging Nettle Fiber

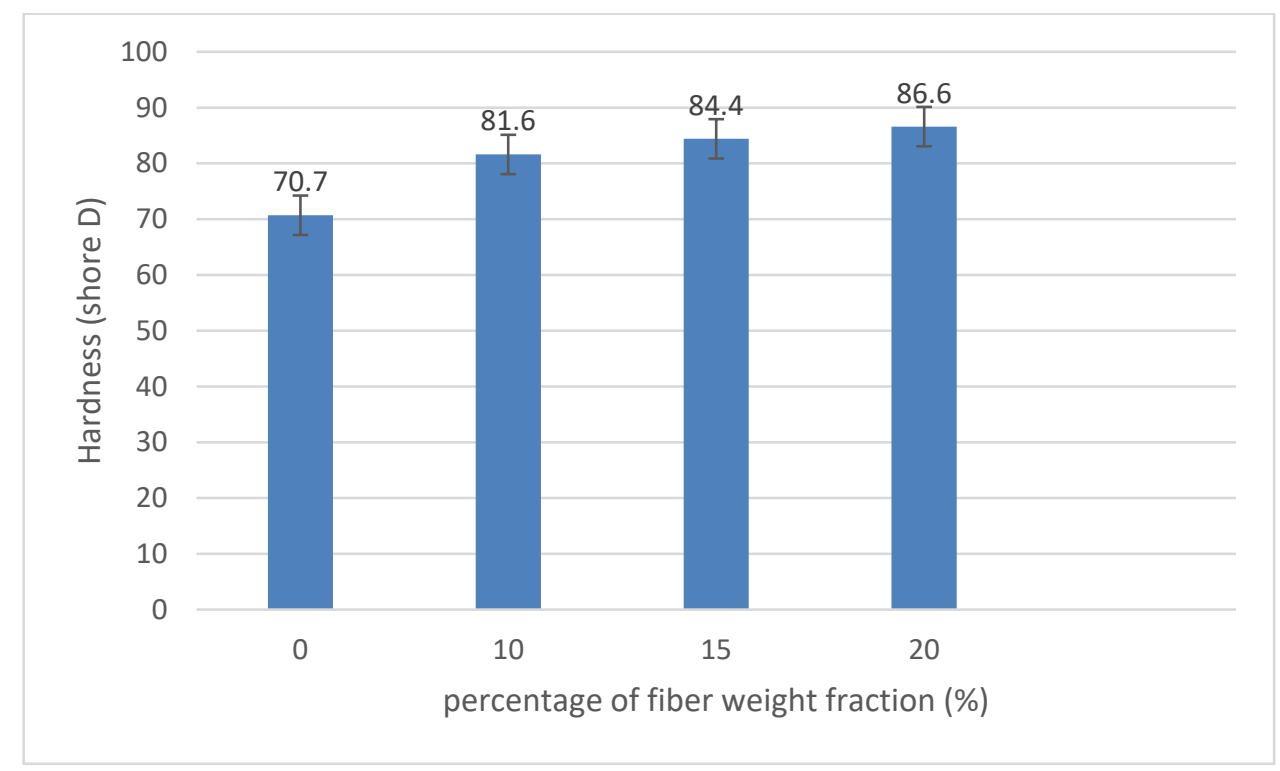

Figure 6. Hardness test results of stinging nettle fiber-reinforced composite with varied fiber weight fraction.

\subsection{The Result of Thermal Conductivity Testing}

Results of thermal conductivity testing were acquired using three samples for triplicate measurements. The average thermal conductivity of the fiber-reinforced composite resulting from varying the fiber weight fraction is illustrated in Figure 7.

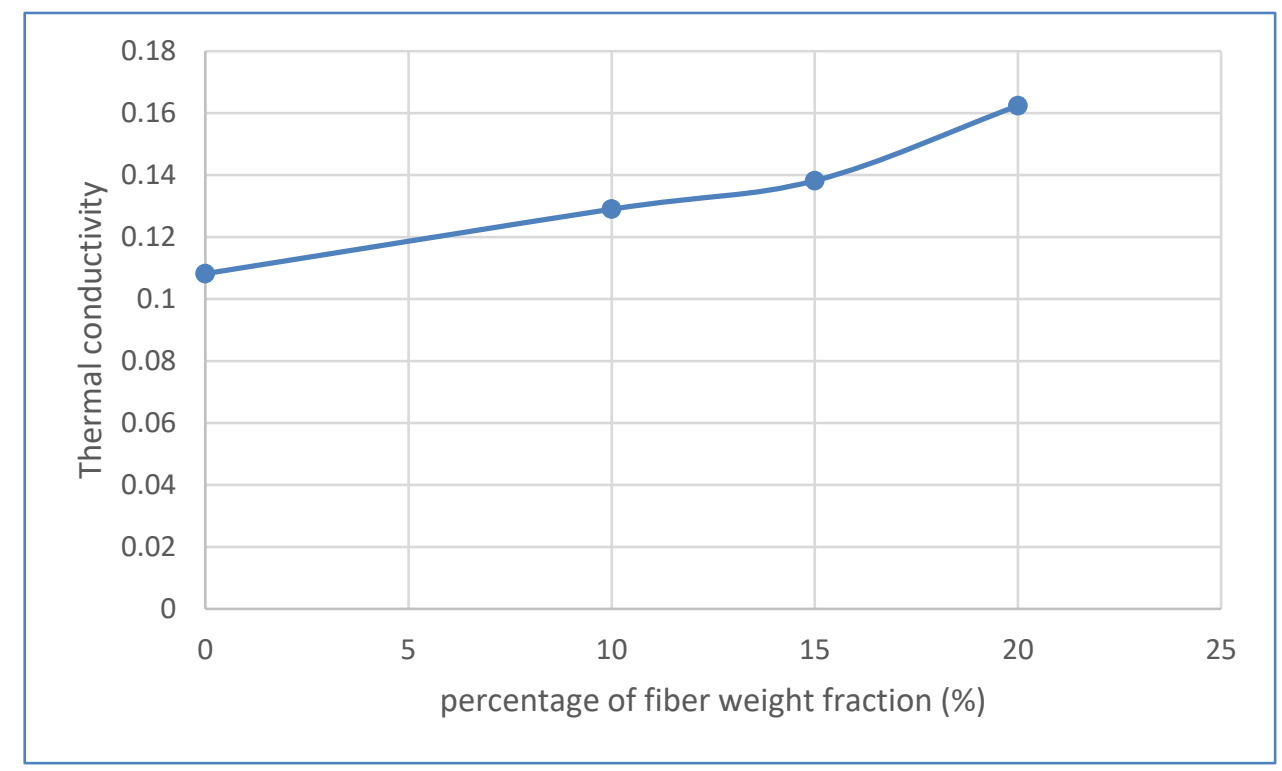

Figure 7. Graph of thermal conductivity of fiber-reinforced composite with varied fiber weight fraction.

The thermal conductivity value for every fiber weight fraction increased as the fiber composition increased. The lowest thermal conductivity was measured for a fiber composition of $0 \%$, with value $0.108 \mathrm{kcal} / \mathrm{ms}{ }^{\circ} \mathrm{C}$, and it increased for the composite with a fiber composition of $10 \%$, with value $0.129 \mathrm{kcal} / \mathrm{ms}^{\circ} \mathrm{C}$. Fiber composition of $15 \%$ resulted in a thermal conductivity of $0.138 \mathrm{kcal} / \mathrm{ms}{ }^{\circ} \mathrm{C}$, and the highest value was with a fiber composition of $20 \%$ which achieved a thermal conductivity of $0.162 \mathrm{kcal} / \mathrm{ms}{ }^{\circ} \mathrm{C}$. From the test data, the 
apparent trend is that the larger the fiber weight fraction in the epoxy resin composite reinforced by stinging nettle fiber, the higher the thermal conductivity.

\subsection{The Result of SEM Test}

The purpose of the SEM test was to support the analysis of composite material failures due to loading. The SEM images of the composite reinforced with 10\%, $15 \%$, and $20 \%$ fiber are shown in Figures 8, 9,10, and 11.

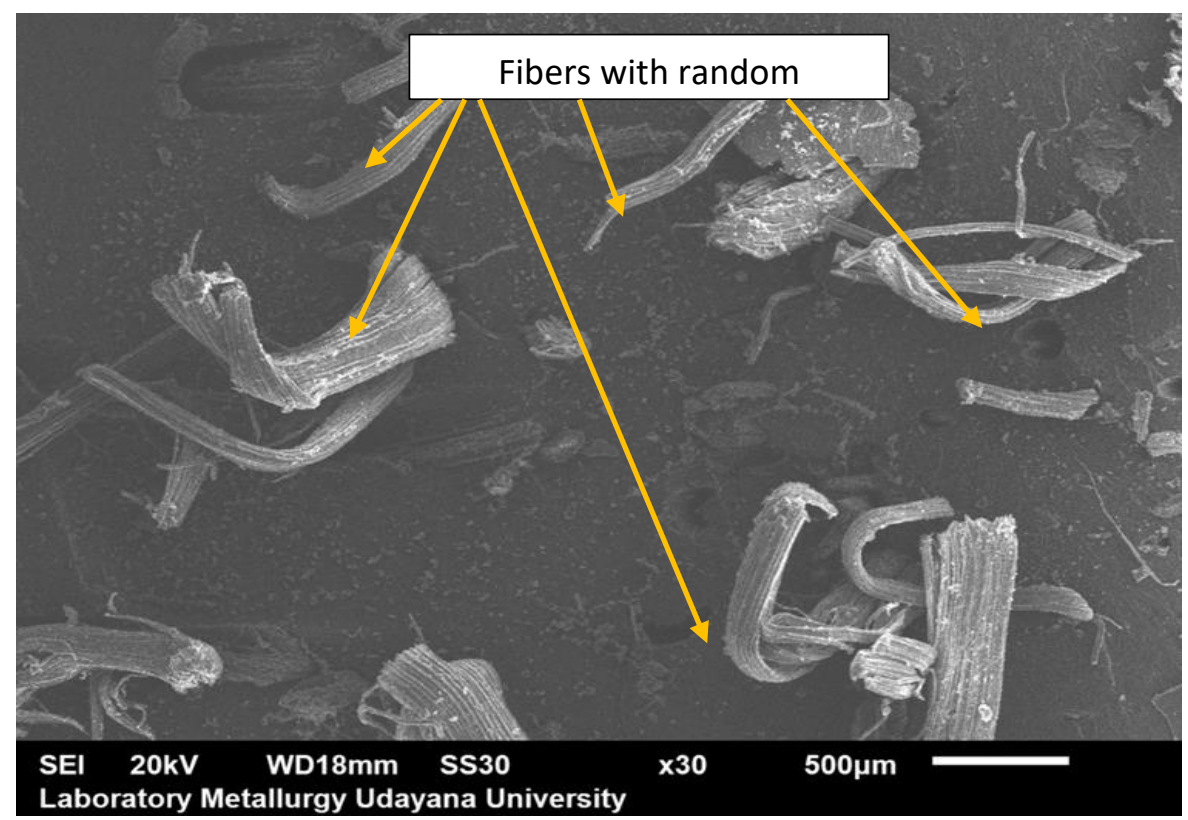

Figure 8. Composite epoxy of 30x magnification

Figure 8 shows that the composite material is produced by random fiber orientation, visible fibers spread on the matrix. Figure 9 is a hardness test sample cut on a composite material with a weight fraction of $10 \%$, visible bad adhesion between the matrix and the fiber, this results in low thermal conductivity due to the inhibited heat flow rate. Conversely, Figures 10 and 11 look good bounding means that the bond between the fiber and the matrix is strong, so that the flow rate of heat smoothly results in increased heat conductivity.

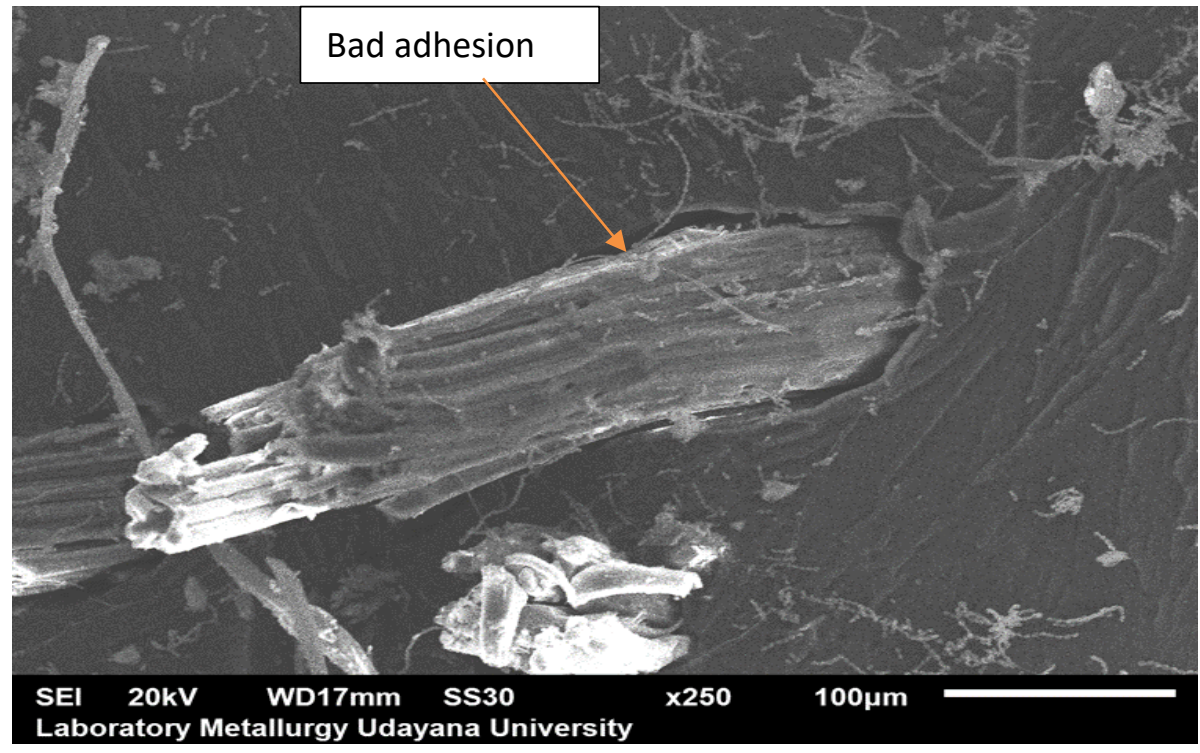

Figure 9. Fracture of $10 \%$ fiber composite 


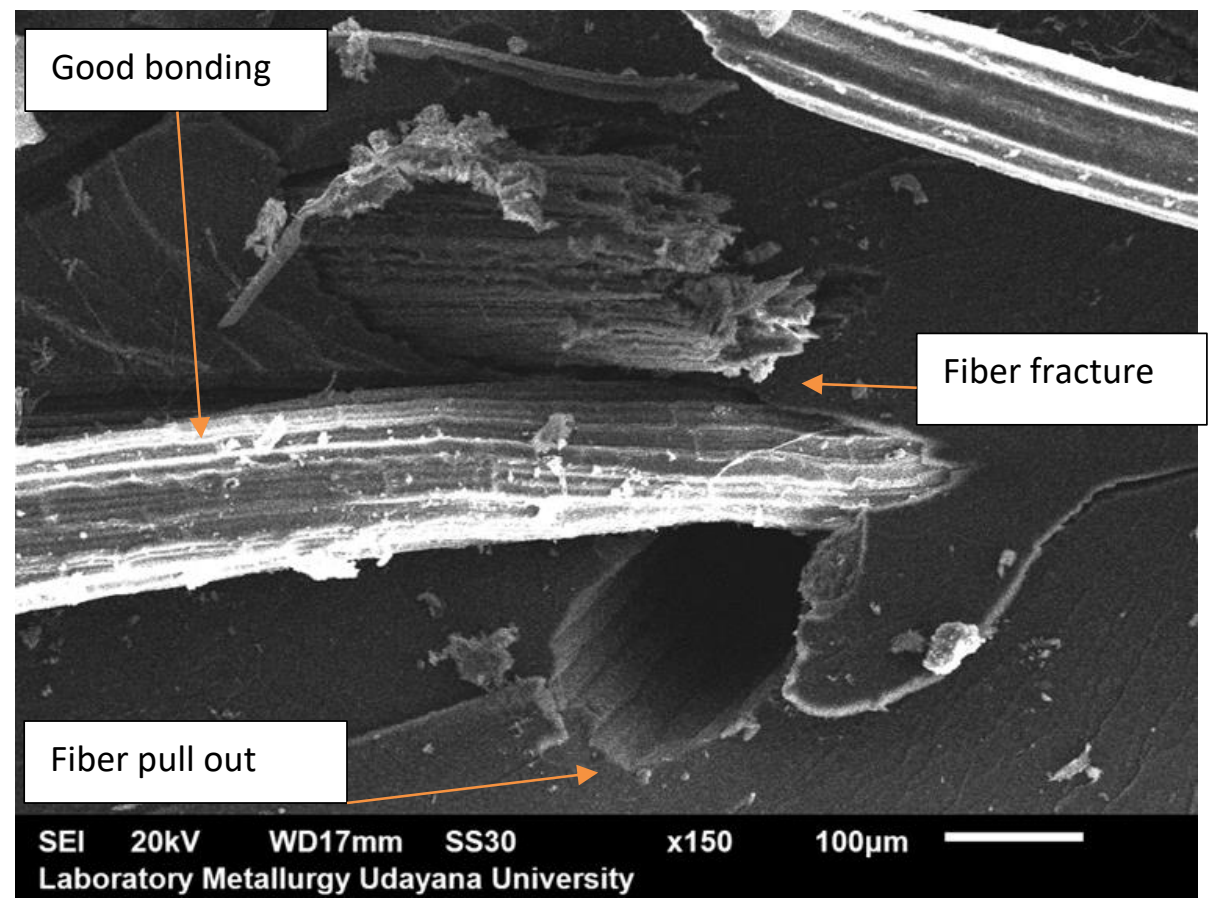

Figure 10. Fracture of $15 \%$ fiber composite

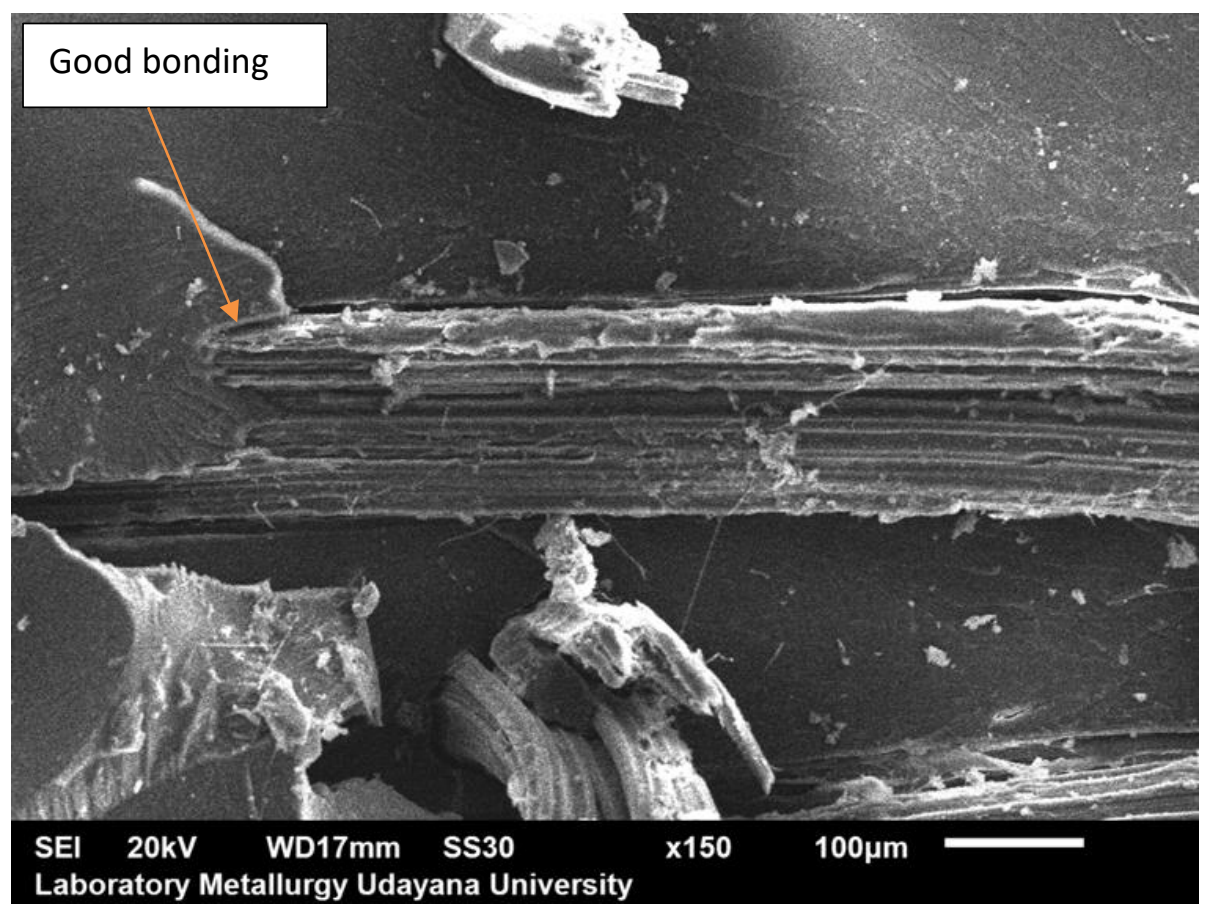

Figure 11. Fracture of $20 \%$ fiber composite

\subsection{Relation between Hardness and Thermal Conductivity}

The results of the regression analysis show that there is a polynomial relationship between the two variables in the mathematical equation in Figure 12, namely, thermal conductivity and hardness. The addition of stinging nettle fiber improved both the thermal conductivity and hardness of the composite. The addition of $10 \%$ fiber weight significantly improved the hardness, while the addition of $20 \%$ fiber weight or more did not significantly improve the hardness compared with the value obtained at $10 \%$. 


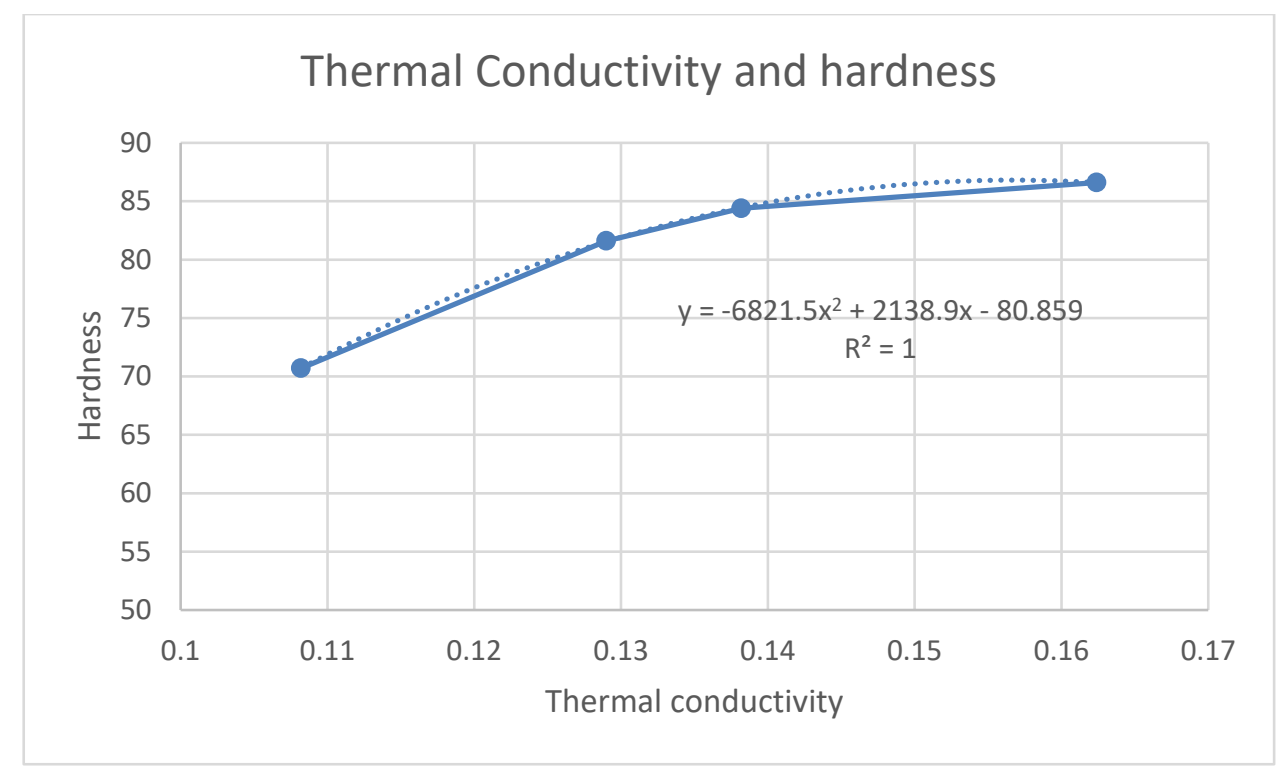

Figure 12. Relation between thermal conductivity and hardness

\section{CONCLUSION}

A composite material was produced and reinforced with stinging nettle fiber. The fiber weight fractions analyzed were $0 \%, 10 \%, 15 \%$, and $20 \%$, and the corresponding hardness values were 70.7, 81.6, 84.4, and 86.6 Shore D; thus, the hardness of the composite increased as the fiber weight fraction of the reinforced composite increased. Similarly, the thermal conductivity of the composite was tested with fiber weight compositions of $0 \%, 10 \%, 15 \%$, and $20 \%$. The respective thermal conductivity values were $0.108,0.129,0.138$, and 0.162 $\mathrm{kcal} / \mathrm{ms}{ }^{\circ} \mathrm{C}$; thus, the thermal conductivity of the composite also increased as the fiber weight fraction increased. The relationship between hardness and thermal conductivity is $\mathrm{y}=$ $6821.5 x^{2}+2138.9 x+80,859$ with a very strong correlation coefficient.

\section{ACKNOWLEDGEMENTS}

The authors thank N.P.G Suardana (corresponding authors : npgsuardana@unud.ac.id), LPPM UNIVERSITAS UDAYANA, Udayana University and Kementerian Riset, Teknologi dan Pendidikan Tinggi.

\section{REFERENCES}

[1] Akgül, Mehmet. Suitability of Stinging Nettle (Urtica Dioica L.) Stalks for Medium Density Fiberboards Production. Composites Part B: Engineering 45(1), 2013, pp. 925929.

[2] Alex, S. and Retnam, S. J. A Review on Degradable Hybrid Natural Fibre. International Journal of Design and Manufacturing Technology (IJDMT) 5(3), 2014, pp. 137-141.

[3] Bacci, L., Baronti, S., Predieri, S. and N. di Virgilio. Fiber Yield and Quality of Fiber Nettle (Urtica Dioica L.) Cultivated in Italy. Industrial Crops and Products 29(2-3), 2009, pp. 480-484.

[4] Bacci, Laura, Sara Di Lonardo, Lorenzo Albanese, Giorgio Mastromei, and Brunella Perito. Effect of Different Extraction Methods on Fiber Quality of Nettle (Urtica Dioica L.). Textile Research Journal 81(8), 2011, pp. 827-837.

[5] Bodros, Edwin and Christophe Baley. Study of the Tensile Properties of Stinging Nettle Fibres (Urtica Dioica). Materials Letters 62(14), 2008, 2143-2145. 
A Study on Correlation Between Hardness and Thermal Conductivity of Polymer Composites Reinforced with Stinging Nettle Fiber

[6] Boufford, D. E. Urticaceae Nettle Family. The Arizona-Nevada Academy of Science 26(1), 1992, pp. 42-49.

[7] Fischer, Holger, Elena Werwein, and Nina Graupner. Nettle Fibre (Urtica Dioica L.) Reinforced Poly(Lactic Acid): A First Approach. Journal of Composite Materials 46(24), 2012, pp. 3077-3087.

[8] Kasim, A.N., Selamat, M.Z., Daud, M.A.M., Yaakob, M.Y., Putra, A. and Sivakumar, D. Mechanical Properties of Polypropylene Composites Reinforced with Alkaline Treated Pineapple Leaf Fibre from Josapine Cultivar. International Journal of Automotive and Mechanical Engineering (IJAME) 13(1), 2016, pp. 3157-3167.

[9] Klimesova, J. Population Dynamics of Phalaris Arundinacea L. and Urtica Dioica L. in a Floodplain during a Dry Period. Wetlands Ecology and Management 3(2), 1995, pp. 7985 .

[10] Liu, Ke, Zhimao Yang, and Hitoshi Takagi. Anisotropic Thermal Conductivity of Unidirectional Natural Abaca Fiber Composites as a Function of Lumen and Cell Wall Structure. Composite Structures 108(1), 2014, pp. 987-991.

[11] Mohapatra, R.C., Mishra, A. and Choudhury, B. Measurement and Prediction of Thermal Conductivity of Hemp Fibre Reinforced Composites. American Journal of Mechanical Engineering 2(4), 2014, pp. 114-119.

[12] Nikmatin, Siti, Achmad Syafiuddin, Ahmad Hong, and Akhiruddin Maddu. Physical, Thermal, and Mechanical Properties of Polypropylene Composites Filled with Rattan Nanoparticles. Revista Mexicana de Trastornos Alimentarios 15(4), 2017, pp. 386-395.

[13] Panthapulakkal, S. and Sain, M. Injection-molded Short Hemp Fiber/Glass Fiberreinforced Polypropylene Hybrid Composites-Mechanical, Water Absorption and Thermal Properties. Journal of Applied Polymer Science, 103(4), 2007, pp. 2432-2441.

[14] Patnaik, Amar, Md Abdulla, Alok Satapathy, Sandhyarani Biswas, and Bhabani K. Satapathy. A Study on a Possible Correlation between Thermal Conductivity and Wear Resistance of Particulate Filled Polymer Composites. Materials and Design, 31(2), 2010, pp. 837-849.

[15] Paukszta, D., J. Ma, J. Ko, and Szostak, M. Polypropylene ( PP ) Composites Reinforced with Stinging Nettle ( Utrica Dioica L .) Fiber. (March 2015), 2013, pp. 37-41.

[16] Ray, D., Sarkar, B.K., Basak, R.K. and Rana, A. K. Study of the Thermal Behavior of Alkali-Treated Jute Fibers. Journal of Applied Polymer Science 85(12), 2002, pp. 25942599.

[17] Sen, Sikander and Ankit. An Experimental Study of Concrete Mix by Adding Natural Fiber (Zucchini Fiber/ Luffa Fiber). International Journal of Civil Engineering and Technology 9(7), 2018, pp. 724-732.

[18] Shetty, Divakara. A Literature Review on Processing and Testing of Mechanical Properties of Hybrid Composites Using Graphene/Epoxy with Alumina. International Journal of Mechanical Engineering and Technology (IJMET) 10(03), 2019, pp. 12631274.

[19] Spa, Intermarp Italia, Centro Elastomeri, and San Giuliano Milanese. "Shore A Hardness and Thickness. Polymer Testing, 7, 1987, pp. 165-175.

[20] Suryawan, I. G. P. A., Suardana, N. P. G., Suprapta Winaya, I. N., Budiarsa Suyasa, I. W. and Tirta Nindhia, T. G. Study of Stinging Nettle (Urtica Dioica 1.) Fibers Reinforced Green Composite Materials : A Review. in IOP Conference Series: Materials Science and Engineering. 2017, pp 7-13.

[21] Di Virgilio, Nicola, Eleni G. Papazoglou, Zofija Jankauskiene, Sara Di Lonardo, Marcin Praczyk, and Kataryna Wielgusz. The Potential of Stinging Nettle (Urtica Dioica L.) as a Crop with Multiple Uses. Industrial Crops and Products 68, 2015, pp. 42-49. 